\title{
Accounting And Economic Implications Of Healthcare Information Technology
}

Paul J. Carruth, Southeastern Louisiana University

Ann K. Carruth, Southeastern Louisiana University

\begin{abstract}
There is a growing consensus that interoperability of health care technology is greatly needed so that data can be effectively and accurately exchanged across provider groups and organizations to provide quality healthcare while reducing the cost of healthcare delivery. Benefits are expected for physician groups, organizations, and patients. Perhaps most exciting is the opportunity for integrated patient and population level data leading to clinical decision support systems which assist with the management of patients by integrating medical knowledge with patient characteristics and generating computer based reminders, alerts, and guidelines. While research supports a multitude of benefits, challenges exist that require long-term commitment before the reality of an integrated healthcare information technology will exist. This article explores the benefits, the barriers, and the long term impact of Healthcare Information Technology on future healthcare delivery systems.
\end{abstract}

\section{INTRODUCTION}

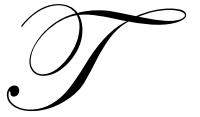

remendous cost and risk of lives are associated with the inability to access medically relevant data. This has become increasingly apparent following the devastation to the healthcare records of thousand of individuals following the flooding of healthcare facilities as a result of hurricane Katrina in 2005. Addressing the high costs associated with medical errors, variable quality of care, administrative inefficiencies, and lack of coordination of care can be accomplished by integrating data with the use of health information technology.

Information technology in the healthcare industry lags behind other industries by 10-15 years (Economist, 2003). Since 1991 multiple messages have been issued by the Institute of Medicine that the computer-based patient record is essential for health care (Institute of Medicine, 1991, 1997). In his 2004 State of the Union address President Bush stated "by computerizing health records, we can avoid dangerous medical mistakes, reduce costs, and improve care". To that end, he wants most Americans to have access to electronic health records by 2014.

\section{WHAT IS HEALTHCARE INFORMATION TECHNOLOGY (HIT)}

Healthcare Information Technology is defined as "the application of information processing involving both computer hardware and software that deals with the storage, retrieval, sharing, and use of health care information, data and knowledge for communication and decision making" (Thompson \& Brailer, 2004). According to the Agency for Healthcare Research and Quality (AHRQ) Health Information Technology is broadly defined as the use of information and communication technology in healthcare and includes, but is not limited to, electronic health records, personal health records, e-mail communication, clinical alerts and reminders, computerized provider order entry, computerized decision support systems, hand-held computers, information resources, and electronic monitoring systems. And there is a need for interoperability, or the ability of IT systems to exchange data, effectively and consistently, so that the use of technology improves the quality of healthcare and reduces the cost of its delivery. 
In the current healthcare system, patient records, usually in the form of paper, are kept at each physician office. This means that if an individual is treated by several different physicians then there are more than one set of patient health records, each residing at a different location. When this individual has to enter the healthcare system, on an emergency basis or otherwise, there is no integration of information from multiple sources. According to the Institute of Medicine, between 44,000 and 98,000 Americans die every year because of medical errors (IOM, 1999). The failure of the healthcare systems' ability to share information has created an environment where the right information is not available to be accessed at the right time, leading to an unacceptable level of risk to patients' wellbeing (Ewing, 2007).

With Electronic Health Records (EHR), longitudinal data for and about persons are collected. This provides the opportunity to electronically access to the population level information to support knowledge and decision-support programs that enhance the safety, quality, and efficiency of healthcare delivery. This "virtual" chart can function as assembled image-based or text based data from various geographic locations. Additionally, integrated patient and population level data will enhance clinical decision support systems which assist with management of patients by integrating medical knowledge with patient characteristics and generating computer based reminders, alerts, guidelines, and other tools to assist with delivering quality healthcare. In a EHR environment the physician is informed of the care needed and is issued alerts regarding overdue labs, medication prescriptions that need renewing, or new information regarding patient populations (Thielst, 2007). Remote patientmonitoring for various tracking mechanisms (e.g. medication compliance) is enhanced when data are transmitted to the providers' offices.

\section{BENEFITS OF HEALTHCARE INFORMATION TECHNOLOGY}

Enthusiasts believe that Healthcare Information Technology can simultaneously improve the quality and productivity of the healthcare system (Goldschmidt, 2005). Healthcare Information Technology systems with interoperability benefit consumers and healthcare organizations alike. Financial benefits include cost reduction, revenue enhancement and productivity gains. Advances in care processes, improved patient outcomes (improvements in safety and quality), and better monitoring of diseases and other health risks improve clinical outcomes. Organizational benefits include improvements in organizational efficacy such as the capacity to adapt to changing technical and operating conditions, such as fluctuations in patient load, acuity, and emergency conditions, and organizational risk mitigation.

One example of the costs associated with healthcare is medication errors. More than 1.5 million Americans are injured by drug errors in hospitals, nursing homes, and doctor's offices. On average, a hospitalized patient is subject to at least one medication error per day (Institute of Medicine, 2006). Healthcare Information Technology will assist organizations in monitoring medication errors by examining the prescribing, dispensing, and administering practices. Several companies, such as Omnicell, have developed systems for medication safety technology. These companies have automated systems for dispensing and tracking medication throughout the hospital enterprise, "from the central pharmacy where the drug is filled, to the bedside where the medication is consumed by the patient" (McEvoy, 2006).

Computerized provider order entry (CPOE) is another example of how informatics is helping to shape the benefits of Healthcare Information Technology. CPOE eliminates reliance on oral and handwritten communication. This in turn minimizes transcription, translation, and misinterpretation of prescriber's orders (Sensmeier, 2005). The Leapfrog Group, a national nonprofit group, has identified the adoption of CPOE as the number one priority for improving patient safety.

Although the adoption of Electronic Health Records (HER) systems is limited, EHR are believed to be beneficial because they reduce cost and improve the quality of care. Table 1 identifies specific examples. 


\begin{tabular}{|c|c|}
\hline Benefits of Electronic Health Record & Examples \\
\hline \multicolumn{2}{|l|}{ Reduced Cost } \\
\hline & Elimination of the need to Maintain paper medical records/charts \\
\hline & $\begin{array}{l}\text { Improved workflow; retrieval of data from various geographic } \\
\text { locations }\end{array}$ \\
\hline & Improved billing \\
\hline & Elimination of transcription \\
\hline & $\begin{array}{l}\text { Automated sharing of information (e.g. test results) among } \\
\text { providers and patients resulting in less duplication }\end{array}$ \\
\hline & Reduced number of office visits \\
\hline & Reduced hospital admissions \\
\hline & Reduced medical errors \\
\hline & Decreased number of malpractice suits \\
\hline \multicolumn{2}{|l|}{ Improved Patient/Population Outcomes } \\
\hline & Organized, accurate clinical data available to authorized users \\
\hline & $\begin{array}{l}\text { Automated sorting and summarization by patient or by diagnostic } \\
\text { code; assists in decision making }\end{array}$ \\
\hline & Instant access to records; directly or remotely \\
\hline & Fewer misinterpretations from hand written orders \\
\hline & $\begin{array}{l}\text { Data used for improved disease management using evidence based } \\
\text { guidelines (e.g. decision support tools) }\end{array}$ \\
\hline & Quality improvement using benchmarking \\
\hline & Expansion of access to affordable care \\
\hline & $\begin{array}{l}\text { Performance Improvement through data mining, gathering data to } \\
\text { support clinical decisions, analyzing causes of diseases, evaluating } \\
\text { intervention effectiveness }\end{array}$ \\
\hline & Improved pharmacologic management \\
\hline & $\begin{array}{l}\text { Access and ability to analyze de-identified data for research } \\
\text { purposes }\end{array}$ \\
\hline & $\begin{array}{l}\text { Surveillance for disease outbreaks including communicable } \\
\text { diseases, disorders unique to bioterrorism, agroterrorism }\end{array}$ \\
\hline
\end{tabular}

\section{BARRIERS TO ADOPTION OF HEALTHCARE INFORMATION TECHNOLOGY}

The overriding barrier of adoption of Electronic Health Records is that even though there is evidence from research studies and long standing claims that savings can be made, there are few organizations that have realized financial gain (Goldschmidt, 2005). A recent study concluded physician offices spent $27 \%$ of revenues on business and insurance related functions compared to hospitals who spent approximately $21 \%$ (Kahn, Kronick, Kreger, \& Gans, 2005). While some argue that Healthcare Information Technology will reduce administrative costs, the process for revamping the entire medical records system would be expensive, especially given that over $50 \%$ of physician groups are small, with fewer than 4 or 5 practicing physicians to share the cost.

Information Technology programs may have risks for data fragmentation, lack of systems integration, and programming flaws. Even though the intended use of Healthcare Information Technology is to prevent errors, the computerization of records may cause mistakes to be made. Health information technology allows the ability to trend the utilization of health care services. Theoretically this will allow the examination and recommendation of cost savings. In reality it may drive the increase use of services, thus increasing expenditures. Without reorganizations of the health care structure, productivity will not be achieved.

When health care decisions are based on technology, errors can occur. Some physician groups resist the advent of standardized care because they fear that the human ability to make decisions will be replaced by 
computerized decision trees. Treating patients based on information in decision support technology may prompt health care practitioners to provide inappropriate or worse, lethal care.

Another barrier is that individuals will be able to manage sensitive personal health information. This concern stems from of security, privacy, and confidentiality of personal records (Goldschmidt, 2005). While many individuals own computers, this cannot be used as an indicator of the ability of individuals to keep secure and manage healthcare information. Health literacy is defined in Healthy People 2010 as: "The degree to which individuals have the capacity to obtain, process, and understand basic health information and services needed to make appropriate health decisions". www.healthypeople.gov. It is estimated that ninety million people in the United States, nearly half the population, have difficulty understanding and using health information (AMA, 1999).

The National Academy on an Aging Society estimated that \$73 billion was spent in 1998 dollars due to low health literacy. http://www.agingsociety.org/agingsociety/publications/fact/fact low.html. These same individuals are being asked to participate in a "consumer driven health care market" to try to force lower costs through awareness and demand for improved management of care. Those who keep personal health records on their home computers may not be able to appropriately interpret the information. Additionally, they are vulnerable to having their files hacked into electronically.

Privacy issues extend to the concern that providers or other governmental agencies may demand electronic access to information. While the Health Insurance Portability and Accountability Act of 1996 was enacted to provide security for all Protected Health Information, including electronic and paper records, the possibilities for abuse are limitless when health records are kept electronically. These legislated privacy protections are one step that has been taken to address the ever increasing concern that breaches in security and leaking of health data will result from the ability to access huge data sources when providers use electronic health records.

\section{ECONOMIC AND POLICTICAL INFLUENCES}

There are several economic and political influences that drive the adoption of Healthcare Information Technology. For over 30 years, the U.S. federal government has invested billions of dollars through grants and contracts to promote the automation of medical information, the use of telemedicine, and the development of Electronic Health Records. In 2004, President Bush established through executive order the position of National Coordinator of Health Information Technology. This position signals the influence of the government in the widespread adoption of Healthcare Information Technology.

The widespread adoption of Healthcare Information Technology will have many challenges. It is estimated that adoption may cost as much as $\$ 1.5$ trillion in the next 15 years (Goldschmidt, 2005). And without overwhelming documented successes, its adoption could falter. The concern is that healthcare organizations are not going to be able to maintain a competitive edge if the investment for Healthcare Information is too great. Resources are needed to cover undocumented workers and aging populations, to upgrade technologies, to market programs and to support other infrastructures.

Even with this competition for limited resources, there are indications that Healthcare Information Technology will continue to grow within health care systems. The hospital segment has over the last several years increased their Electronic Health Records budgets to 3-4\% of their Information Technology budgets (McEvoy, 2006), increasing the pressure to implement its use throughout the healthcare system.

In order for this system to work there must be penetration of use among physician practices. A study by the RAND corporation in 2005 reported an adoption rate for Electronic Health Records systems in U.S. physician offices ranged from $15 \%$ to $20 \%$, with offices of four or fewer physicians (most of the U.S. offices) having lower rates of adoption (Hillestad, 2005). One challenge is that physicians are reluctant to change the workflow of their office visits. Physician practices are largely small businesses and they must decide whether or not to invest in Healthcare Information Technology when third-party payers may most benefit from the use of HIT. 
A lack of interoperability and the absence of standards may create reluctance on the part of the practitioner to adopt Electronic Health Records. Certification of Electronic Health Records requirements implemented and then later revised will drive the need for new equipment or software, adding to the expense of adoption and use. Initial efforts have been made to address the issue of certification. The Office of the National Coordinator for Health Information was established in 2005 and one of the contracts awarded was the Certification Commission for Healthcare Information Technology (CCHIT). The work of this commission is to develop a certification process for health IT products. In 2006, the CCHIT certified the first 37 ambulatory, or clinician office based electronic health record products. This certification assures providers that products meet criteria for functionality, security, and interoperability (DHHS, 2006). This saves time for providers when trying to decide whether and what to buy for their practice. Certification is granted after a four to six hour testing process of scenarios (Nagy, 2006). A CCCHIT proctor and three jurors witnessing the testing period vote on the functionality and interoperability of the system. If compliant with standards, certification is awarded. The potential of breach in security is tested by having a juror evaluate whether logins and audit trails meet standards. This phase of certification assures that information remains private.

\section{SUMMARY AND CONCLUSIONS}

Perhaps the greatest benefit of Healthcare Information Technology is the potential for standardization of health practices as a result of collecting and analyzing large data sources. Scientific evidence, best practices and decision-support technology that is widely accepted and adopted as part of the practitioners practice has tremendous potential for influencing health care delivery. Changing the culture of medical practice to incorporate health information technology will require a systematic overhaul of the current system. For example, successfully implementing HIT will require good technical support and implementation and training and evaluation. Health care curricula will need to include courses on health services research and the role of health information technology. And consumers will need to understand the use of information and the ability to electronically manage personal records.

\section{REFERENCES}

1. $\quad$ Ewing, L. (2007). Electronic health records. Searcher, 15 (5). 49-51.

2. Goldschmidt, P. (2005). HIT and MIS: Implications of health information technology and medical information systems. Communications of the ACM. 48 (10), 69-74.

3. Hillestad et al (2005). Can electronic medical records systems transform health care? Potential health benefits. Health Affairs, 24, 1103-1117.

4. Institute of Medicine. The computer -based electronic medical record: An essential technology for healthcare. NAP, Washington, DC, 1991 (revised 1997).

5. Institute of Medicine. To err is human: building a safer health system, National Academies, 1999 [www.iom.edu].

6. $\quad$ Is IT the cure? Economist (May 8, 2003) .

7. Kahn, J. Kronick, R., Kreger, M., Gans, D. (2005). The cost of health insurance administration in California: Estimates for insurers, physicians, and hospitals, Health Affairs, 24 (6). 1629-1639.

8. McEvoy, T.J. (2006). Wall Street Transcript. 4/17/2006, Vol 17, Issue 15, p1, 9p.

9. Nagy, B. (2006, June). Setting guidelines for electronic health records is complex. Managed Healthcare Executive, 16(6) 60-61.

10. Report on the Council of Scientific Affairs, American Medical Association, JAMA, Feb 10, 1999 Preventing Medication Errors, Institute of Medicine, July 20, 2006.

11. Sensmeier, J. (2005). Here and now: Healthcare's top 10 IT breakthroughs. Nursing Management. Oct supplement, 36, 8-11.

12. Thielst, C. (2007). The new frontier of electronic, personal, and virtual health records. Journal of Healthcare Management, 52 (2). 75-78.

13. Thompson, T., \& Brailer, D. (2004) IT strategic framework. DHHS, Washington DC. U.S. Department of Health and Human Services. Health Information Technology Initiative. Major Accomplishments: 20042006. 
NOTES 